\title{
AGRICULTORES FAMILIARES, ¿Y DESPUÉS? IMPACTO DE LA INCLUSIÓN DE ORGANIZACIONES INDÍGENAS A LA ESTRUCTURA ESTATAL
}

\author{
FAMILY FARMERS, AND AFTERWARDS? THE IMPACT OF THE INCLUSION OF \\ INDIGENOUS ORGANIZATIONS IN THE STATE STRUCTURE
}

\author{
Marina Weinberg ${ }^{1}$
}

\begin{abstract}
En este artículo examino la instauración en Argentina del paradigma de lo que se denominó desde mediados del 2000, el sector de la Agricultura Familiar. En particular, indago desde un acercamiento etnográfico, la estructura y funcionamiento de la Secretaría de Agricultura Familiar y analizo cómo la misma desarrolló su vinculación con la organización indígena Qullamarka, en la provincia de Salta. Presto atención a las maneras en las cuales esta organización se reformuló dentro de un contexto político en el cual, hasta cierto punto, se favoreció la emergencia y crecimiento de organizaciones de base, a la vez que se presentó una estructura que de alguna manera limitaba y moldeaba su funcionamiento. Observo entonces la manera en la cual algunas comunidades indígenas se incorporaron como agricultores familiares a políticas públicas, y cómo esa reconfiguración modificó su vínculo con el Estado, tanto provincial como nacional. Así como también, el impacto que tuvo dentro de la propia organización.

Palabras claves: pueblos indígenas, Estado, agricultura familiar, noroeste argentino.
\end{abstract}

In this article I examine the establishment in Argentina of the paradigm of what has been described, since mid-2000, as the Family Farming sector. From an ethnographic approach, I consider in particular the structure and functioning of the Family Farming Department, and I examine how this office related to the indigenous organization Qullamarka in the Salta province. I pay attention to the ways in which this organization was reformulated within a political context in which, to some extent, the emergence and development of grassroots organizations was favored, while at the same time there was a structure that limited and shaped its functioning. I observe the ways in which some indigenous communities were incorporated as family agriculturalists to public policies and how this reconfiguration modified their relation with the state, both at the provincial and national levels, as well as the impact that this had inside their own organization.

Key words: Indigenous peoples, State, family agriculture, northwestern Argentina.

Uno de los debates fundamentales que dejó latente el período político finalizado en diciembre del 2015 en Argentina, fue sobre el rol del Estado. Luego de más de una década de políticas neoliberales extremas que habían restringido el alcance de los poderes públicos, con su auge a lo largo de la década de los noventa, una de las propuestas políticas más claras del período iniciado por Néstor Kirchner en 2003, y proseguido por Cristina Fernández de Kirchner hasta 2015 (ambos representando a la coalición Frente para la Victoria), fue la recuperación del espacio estatal con un rol mucho más activo, con una gran ampliación de sus funciones y una vasta llegada a la población. Inclusive, se instaló un uso discursivo de la conceptualización del "retorno estatal" como parte de su estrategia política. Con aquel giro, en consonancia con un cambio de rumbo a nivel regional, durante la primera década del milenio, el Estado volvió a ser un fuerte actor en el escenario político y económico del país.

Años atrás, a lo largo de la década de los noventa, bajo el gobierno de Carlos S. Menem (representando al Partido Justicialista), el país había padecido una reducción de la esfera estatal, que bajo la lógica

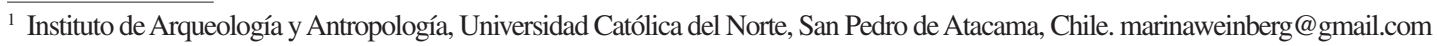

Recibido: mayo 2018. Aceptado: enero 2019.
}

http://dx.doi.org/10.4067/S0717-73562019005001305. Publicado en línea: 17-junio-2019. 
empresarial de la "ineficiencia" de los organismos y servicios públicos, privatizó la mayor parte de la estructura. Los objetivos administrativos de aquel entonces, fueron ofrecidos como la solución a las enormes "pérdidas" que generaba el Estado, mientras se beneficiaba el ingreso de capitales extranjeros de la mano de préstamos de los grandes bancos (principalmente Banco Mundialy Banco Interamericano de Desarrollo); los cuales impusieron sus propias agendas, así como aumentaron exponencialmente la deuda externa del país. Extremas políticas de ajuste generaron flexibilización laboral, desindustrialización, y el consecuente empobrecimiento de la mayor parte de la población, provocando una altísima exclusión social. Los sectores nacionales dominantes de aquel período, tomaron el discurso imperante de la época: una "misión moral" que resguardaba la receta neoliberal, la cual era ofrecida como la única solución posible para reorganizar los países a lo largo de la región latinoamericana (Friedman 2003; Gledhill 2004; Harvey 2003, 2005), donde la mayoría de los mismos se encontraba inmersa en duras crisis político-económicas. Los discursos imperantes entonces, provenientes de las grandes agencias multilaterales de financiamiento, encontraron rápidamente aliados locales en el país.

En el año 2001, bajo el gobierno de Fernando de La Rúa quien representaba a la Alianza, una muy heterogénea coalición conformada por diversos segmentos políticos, el país llegó a la cima de una crisis económica, política, institucional y social, que tuvo su estallido a fines de aquel año, en los tristemente ya conocidos ' 19 y 20 de diciembre'. Como resultado se dio la renuncia del presidente y dos años de inestabilidad política con una seguidilla de cinco funcionarios ejerciendo dicho cargo en tan solo dos semanas. Habiendo colapsado el modelo de extremo ajuste que se venía desarrollando por años, con una histórica presencia popular en las calles de todo el país, las cuales rechazaban las medidas que agobiaban a la mayor parte de la población, se inició un proceso de recuperación del espacio público.

En mayo de 2003, Néstor Kirchner ganó las elecciones presidenciales con la alianza peronista Frente para la Victoria. Luego de una década de políticas orientadas a la reconstrucción y fortalecimiento de instituciones estatales, que será desarrollada a continuación, aunque manteniendo y hasta profundizando un modelo de neoliberalización agraria (Lapegna 2017), una vez más en correspondencia con un giro político que se observó a nivel regional, a fines del año 2015, la fuerza política de centro-derecha Cambiemos, liderada por el empresario Mauricio Macri, ganó las elecciones presidenciales. Este nuevo gobierno en muy corto tiempo ha fortalecido las fuerzas de seguridad, ha provocado despidos masivos de empleados públicos, reduciendo así la dimensión estatal fortalecida (aún bajo enormes críticas) en el período anterior, ha incrementado el costo de los servicios básicos, ha inducido a la reducción del sector privado de pequeñas y medianas empresas, favoreciendo el crecimiento de las grandes corporaciones, y ha generado un nivel de inflación por el cual los precios de la canasta básica se han disparado, alejándose del valor real de los salarios, entre otras medidas.

En el contexto presentado, es claro que el país entró en un nuevo ciclo político- económico, con trazos más que autoritarios, en el cual además se vuelve a criminalizar la protesta social como ya había sucedido a lo largo de la década de los noventa. Hay nuevamente un movimiento político regional, hacia estrategias liberal-conservadoras, con una reapertura a capitales extranjeros y al consecuente endeudamiento público, y con una fuerte inclinación autoritaria, aunque el discurso de la preeminencia del Estado aún persiste (Weinberg 2017). A poco más de dos años en el poder, el gobierno de Macri no ha hecho más que tomar medidas abusivas y profundizar las líneas más siniestras del modelo neoliberal, a pesar de lo cual, hablar tan pronto de un retorno a los noventa, sería simplificar muy rápidamente la compleja situación actual que aún se está presentando.

Considerando entonces estos vaivenes políticos de las últimas décadas, y la consistente ausencia de estrategias estatales orientadas a afianzar los derechos de los pueblos indígenas, en el presente artículo intento examinar desde una perspectiva antropológica, ¿bajo qué circunstancias y con qué estrategias se conformaron en Argentina espacios de atención al desarrollo rural en las últimas dos décadas?, y más específicamente, ¿de qué manera se han propuesto y diseñado políticas de atención a los pueblos indígenas, incorporándolos a estos dispositivos? Y finalmente, ¿de qué manera las organizaciones sociales que se agrupan en el sector indígena rural se han posicionado y configurado a la luz de los escenarios cambiantes?

\section{Presentación}

Para desarrollar la investigación a partir de la cual resulta este artículo, tomé como el principal eje analítico, la instauración del paradigma de lo que se denominó desde mediados de los 2000, el sector de la Agricultura Familiar (AF). Indago desde un acercamiento etnográfico, la estructura y funcionamiento de la actual Subsecretaría de Agricultura Familiar y Desarrollo Territorial 
Institucional (SsAF), dentro del Ministerio de Producción y Trabajo ${ }^{1}$. En particular, presto atención a la delegación de la provincia de Salta e indago cómo la SsAF ha desarrollado su vinculación en los últimos años con la organización indígena de la etnia kolla Qullamarka.

El trabajo de campo el cual da como resultado este artículo, se llevó a cabo de manera ininterrumpida entre los años 2010 y 2016, con actualizaciones más esporádicas hasta la fecha. A pesar de ello, considerando investigaciones anteriores, se contaba con conocimiento previo de la región específica del norte de la provincia de Salta, mayormente del departamento de Iruya, en donde se ha realizado trabajo desde el año 2002 (observando tanto el nivel de estructura estatal, como proyectos de desarrollo local y funcionamiento de organizaciones indígenas).

Para abordar las problemáticas particulares referidas a la emergencia de la figura de la Agricultura Familiar dentro del campo de desarrollo de las comunidades indígenas, se llevó a cabo observación participante en diversos ámbitos, visitas a comunidades indígenas involucradas, visitas con agentes de la SsAF de las provincias vecinas de Salta y Jujuy, participación en capacitaciones tanto a nivel provincial como en las comunidades, entrevistas en profundidad a coordinadores provinciales de la SsAF, a técnicos profesionales e idóneos de la misma, y finalmente a líderes y miembros de comunidades indígenas involucradas en los procesos estudiados. También se realizaron entrevistas a representantes estatales con cargos públicos en oficinas provinciales (Salta) que tienen vínculo con la SsAF y con las comunidades indígenas.

El trabajo de campo se llevó a cabo principalmente entre la capital salteña, el departamento de Iruya (2800 msnm) y el departamento de Orán (400 msnm). Dentro de estos dos departamentos, se trabajó en las localidades del pueblo de Iruya, Colanzuli, San Isidro, Isla de Cañas, y ciudad de San Ramón de la Nueva Orán. Para completar la información más administrativa, también se llevó a cabo trabajo en la Ciudad Autónoma de Buenos Aires y en algunos lugares de la provincia de Jujuy (San Salvador de Jujuy) (Figura 1).

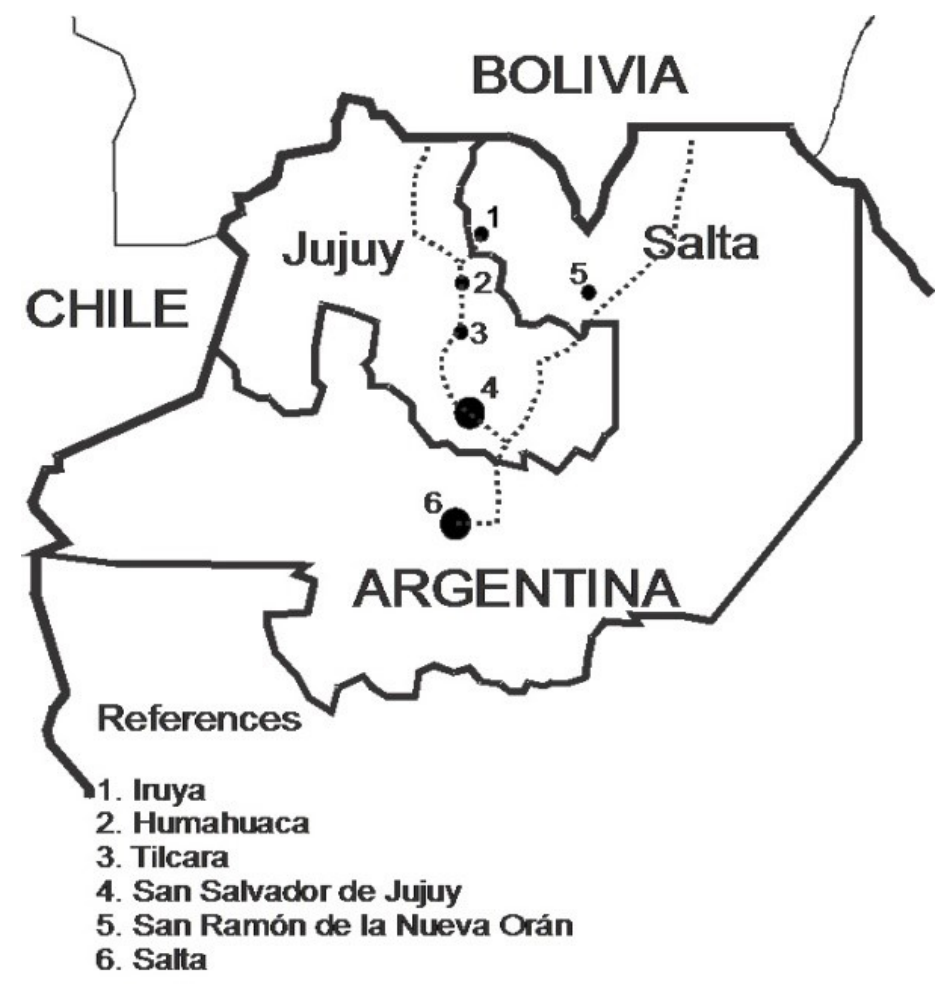

Figura 1. Mapa localidades (Weinberg 2013:17).

Map of Localities (Weinberg 2013:17). 
A través de este estudio, procuro analizar la manera en la cual la organización indígena Qullamarka está siendo constantemente reformulada; primero, dentro de un contexto político en el cual, hasta cierto punto, se favoreció la emergencia y crecimiento de organizaciones de base, a la vez que se presentó una estructura que de alguna manera limitaba y moldeaba su funcionamiento, y segundo, con la interrupción de dicho proceso por un decisivo cambio político a nivel nacional. En otras palabras, observo aquí la manera en la cual algunas comunidades indígenas organizadas se incorporaron como "agricultores familiares" a políticas públicas, y cómo esa reconfiguración modificó su vínculo con el Estado, tanto a nivel provincial como nacional; asimismo, indago sobre el impacto que tuvo este cambio de estrategia dentro de la propia organización local.

El noroeste argentino (NOA, donde se encuentran las provincias de Salta y Jujuy), junto con el noreste (NEA), representa una de las regiones más pobres del país, con elevados índices históricos de pobreza, malnutrición, analfabetismo y desempleo. En esta región también se encuentra la población indígena más numerosa a nivel nacional, la cual ha sido siempre altamente activa políticamente. Asimismo, desde las primeras décadas del siglo XX, Salta fue uno de los focos productivos más influyentes en la economía y políticas nacionales, a costa de la usurpación de territorios indígenas que permitieron la instalación de masivos ingenios azucareros y tabacaleros, construidos sobre la explotación de fuerza de trabajo indígena² ${ }^{2}$ A lo largo de las últimas décadas, corporaciones transnacionales han desarrollado actividades tales como la producción extensiva de soja, tala de bosques y minería, explotado la provincia de forma sumamente agresiva, afectando bosques, tierras, aguas y recursos minerales (Weinberg 2013, 2017). Esta situación ha dejado cada vez más expuesto el enorme problema aún irresuelto de los conflictos por la tenencia y uso de los territorios ancestrales de los pueblos indígenas.

Esta investigación se enmarca en propuestas teóricas que consideran al Estado no como un ente monolítico sino como un engranaje dentro de un encuadre político, en el cual diversos sectores negocian tensionando intereses y fuerzas sociales (Abrams 1988; Mann 1993; Nugent 2004; Vilas 2011; Wolf 2001). Asimismo, el estudio se apoya en teorías bottom-up (de abajo hacia arriba) que entienden al Estado como el producto de relaciones sociales concretas, observables y analizables, en sus más íntimas esferas de la vida cotidiana. En consecuencia, suscribe a los supuestos sobre los procesos de formación del Estado que sostienen que los mismos pueden ser afectados y hasta modificados a través de acciones de actores subalternos (Gledhill 2000, 2008; Nugent 1997; Sayer 1994). En este marco, el concepto de hegemonía resulta fundamental para explorar el Estado y organizaciones políticas, considerando esta negociación de fuerzas como una puja dialéctica constante, entre sectores dominantes y subalternos (Gramsci 1971). La hegemonía como relación, no puede existir sin acciones contrahegemónicas, y se entiende entonces que no es una entidad impuesta por grupos dominantes sino un espacio político en constante negociación, con resultados cambiantes, los cuales arriban a diversos "pactos" políticos, en diferentes momentos históricos, que permiten, en definitiva, la gobernabilidad. Aquí entonces se parte de una noción de hegemonía que nos permite ir más allá del análisis de los procesos homogeneizantes de formación del Estado nacional, como netamente impuestos sobre las poblaciones indígenas; se observan procesos de resistencia y negociación sumamente complejos a lo largo de la historia y hasta la actualidad; aunque sin perder de vista los mecanismos arbitrarios y destructivos que han desplegado las clases dominantes contra los pueblos originarios por más de dos siglos (Mallon 1995).

\section{Agricultura familiar como estrategia y como actor}

En pleno auge neoliberal, Argentina se sumó a las reformas constitucionales que se enmarcaban en el Convenio 169 de la OIT, incorporando en el año 1994 el artículo 75 inciso 17, el cual reconocía los derechos colectivos de los pueblos indígenas, junto con su preexistencia étnica y cultural. Dicha reforma garantizaba la educación intercultural bilingüe, personería jurídica, y posesión y propiedad de los territorios comunitarios que tradicionalmente ocupan. Aquel contexto de adopción de un discurso de multiculturalismo neoliberal, con fuerte intervención de organismos internacionales de financiación marcó la década de los noventa, generando cierta apertura en los debates, pero a la vez, alojando enormes contradicciones y complejidades que subsisten hasta hoy (Hale 2004).

Los pueblos indígenas procuraron en los años posteriores a la reforma constitucional, entrar en el modelo del multiculturalismo neoliberal gozando de ciertos beneficios a la vez que desarrollando alternativas políticas que transformaran la noción liberal de 'diversidad' tolerada por dicho modelo (de la Cadena 2006; Hale 2002; Postero 2007). De la misma manera, lucharon y recibieron un paquete muy amplio de reconocimientos, a pesar de lo cual algunas demandas más profundas que cuestionaban 
rasgos como autonomía, plurinacionalidad y autodeterminación, no fueron discutidas (Weinberg 2013). Se incorporó entonces oficialmente el lazo entre identidad y territorio (Briones 2005; Gordillo y Hirsch 2003), aunque de alguna manera cristalizando las identidades indígenas. En este sentido, si bien se fueron conformando bases fuertes para las subsecuentes luchas por la devolución de territorios indígenas, se fue haciendo evidente que el reconocimiento constitucional no garantizaba la inclusión política o económica de estos sectores. Fue así que, desde principios de la década de los noventa en Argentina, así como sucedió en la mayor parte de la región latinoamericana, se produjo una re-emergencia de movimientos indígenas basado en un fuerte clivaje étnico, en un contexto general de exclusión social que no encontraba límites.

Al presente, ningún gobierno argentino ha logrado generar espacios o mecanismos que garanticen la totalidad de los derechos obtenidos hace tan solo veinte años. En el año 1985, se creó el Instituto Nacional de Asuntos Indígenas (INAI) mediante la sanción de la Ley 23.302 "sobre Política Indígena y apoyo a las Comunidades Aborígenes. Objetivos. Comunidades Indígenas. Instituto Nacional de Asuntos Indígenas. Adjudicación de Tierras. Planes de Educación, Salud y Vivienda". A pesar de la existencia por más tres décadas de dicho organismo, un informe de la Auditoría General de la Nación del año 2016 declara de manera axiomática que: "En nuestro país la Constitución Nacional y el Convenio 169 OIT, aprobado por Ley Nacional 24.071, aseguran a los pueblos indígenas la participación en la gestión de sus recursos naturales, el reconocimiento de la posesión y propiedad de las tierras que tradicionalmente ocupan y el acceso a programas de desarrollo. Sin embargo, hay una brecha significativa entre el marco legal establecido y su implementación efectiva, lo que configura un retraso en la aplicación del marco internacional" (AGN 2016:36). Dicho informe, además, denuncia las falencias de la institución exponiendo que: "El INAI no ha sido dotado con los recursos humanos, materiales y tecnológicos suficientes para cumplimentar las tareas encomendadas. Los empleados carecen de estabilidad laboral" (AGN 2016:22), y concluye, "es un organismo que carece de presupuesto y capacidad institucional para mediar e intervenir en las principales actividades que afectan la vida de las comunidades" (AGN 2016:36).

Dada la reducida y casi nula presencia de políticas orientadas a los pueblos originarios, a partir del año 2005 se desplegó una estrategia en las zonas rurales, de incorporación de estas poblaciones como beneficiarias en calidad de 'pequeños productores' o 'agricultores familiares'. En la provincia de Salta, se produjo una agrupación de lo que comúnmente se denominan 'asuntos indígenas' (como se dijo a cargo del INAI), a las políticas de intervención de la entonces Subsecretaría de Agricultura Familiar (SsAF), la cual contaba con un presupuesto propio y equipo técnico mucho más amplio.

La creación de la SsAF constituyó una política de Estado orientada al sector de la agricultura familiar (AF), conjuntamente con la creación de otros espacios ${ }^{3}$. Junto con la Subsecretaría, se crearon una gran cantidad de espacios que apoyan al sector denominado $\mathrm{AF}$, el cual en palabras de una ingeniera agrónoma especialista en desarrollo rural, "se contrapone a la agricultura empresarial o patronal, en general identificada con la producción de granos y pecuaria extensiva". Al mismo tiempo claro está, desde las políticas macro estructurales de gobierno, no se dejó de lado la promoción y el interés por el desarrollo de colosales emprendimientos agroindustriales como por ejemplo de producción sojera, con los consecuentes desmontes, los cuales han sido mayormente financiados y administrados por grandes grupos empresariales (tanto nacionales como internacionales), precisamente en detrimento del sector de los pequeños campesinos. Muchos de los cuales en la región del NOA son poblaciones indígenas (Weinberg 2013).

La delegación de la SsAF de la provincia de Salta en aquel momento, cuando la oficina estaba dentro de la égida del Ministerio de Agricultura, Ganadería y Pesca, por intereses particulares a su coordinación y equipos de trabajo en terreno, procuró no solamente establecer diálogo sino abrir y fortalecer la participación de organizaciones indígenas al espacio estatal (Figuras 2 y 3). En 2015, se le subiría el status a tal oficina, pasando a ser Secretaría, y a través de los últimos dos años, en concordancia con el poco interés del gobierno actual sobre este sector, se la volvió a reducir a Subsecretaría, habiendo pasado por los Ministerios de Agroindustria, Desarrollo Social, y quedando actualmente, en Producción y Trabajo.

Más allá de cierta distancia existente con los criterios nacionales dependiendo de quién estuviese a cargo de la oficina, quien fuera en su momento la coordinadora provincial, conservando su cargo por un tiempo superior a todas las otras dependencias del país (quedando en su cargo por más de dos décadas), me compartió en una entrevista que "no todo es tan lineal. Inclusive dentro del Estado siempre hay gente interesada en desafiar las direcciones que se establecen desde arriba, y muchas veces de manera distinta se va tomando ventaja de las grietas del sistema". 


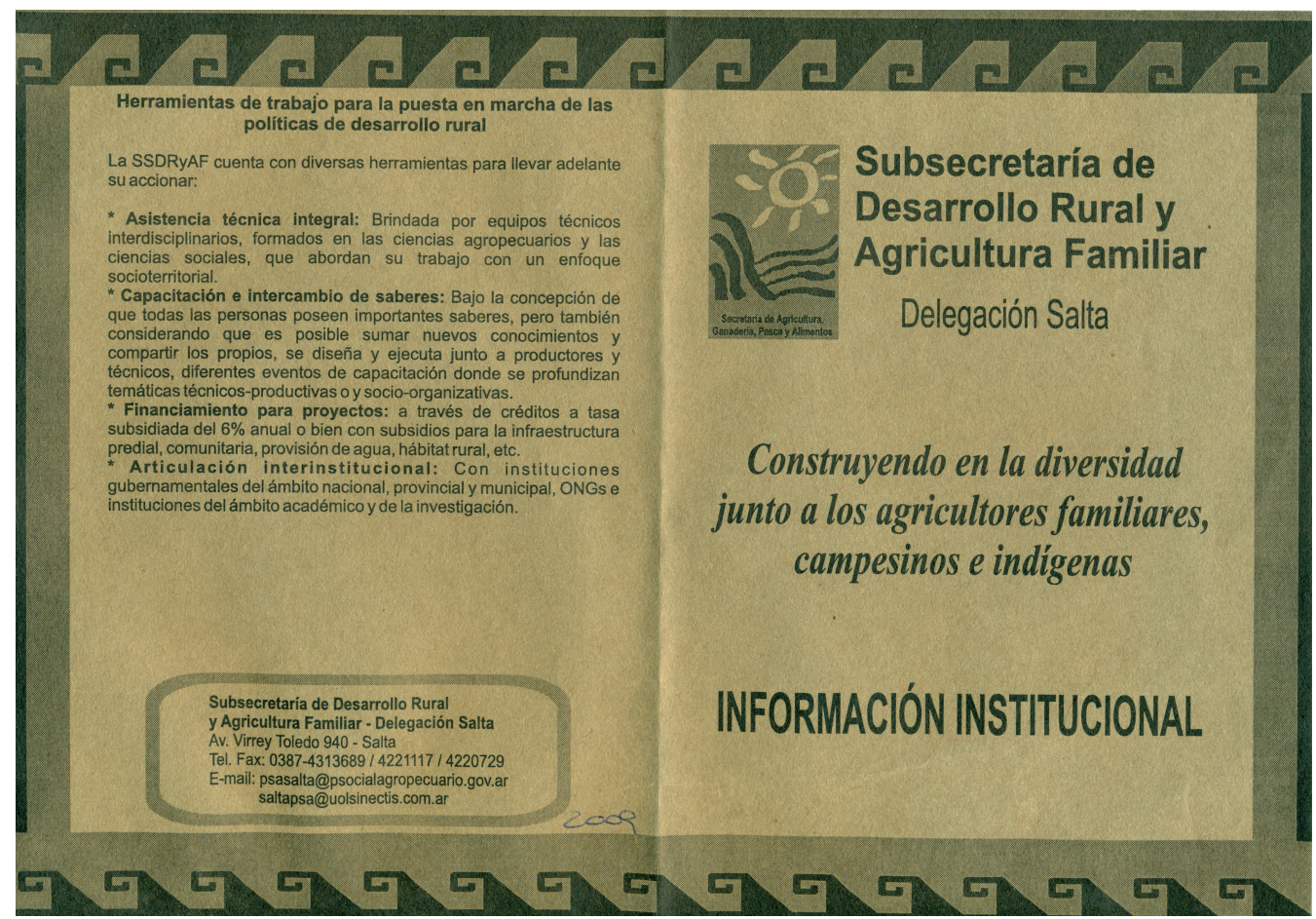

Figura 2. Subsecretaría de Desarrollo Rural y Agricultura Familiar - Delegación Salta "Información Institucional” 1. Undersecretary of Rural Development and Family Farming - "Institutional Information" Salta Office 1.

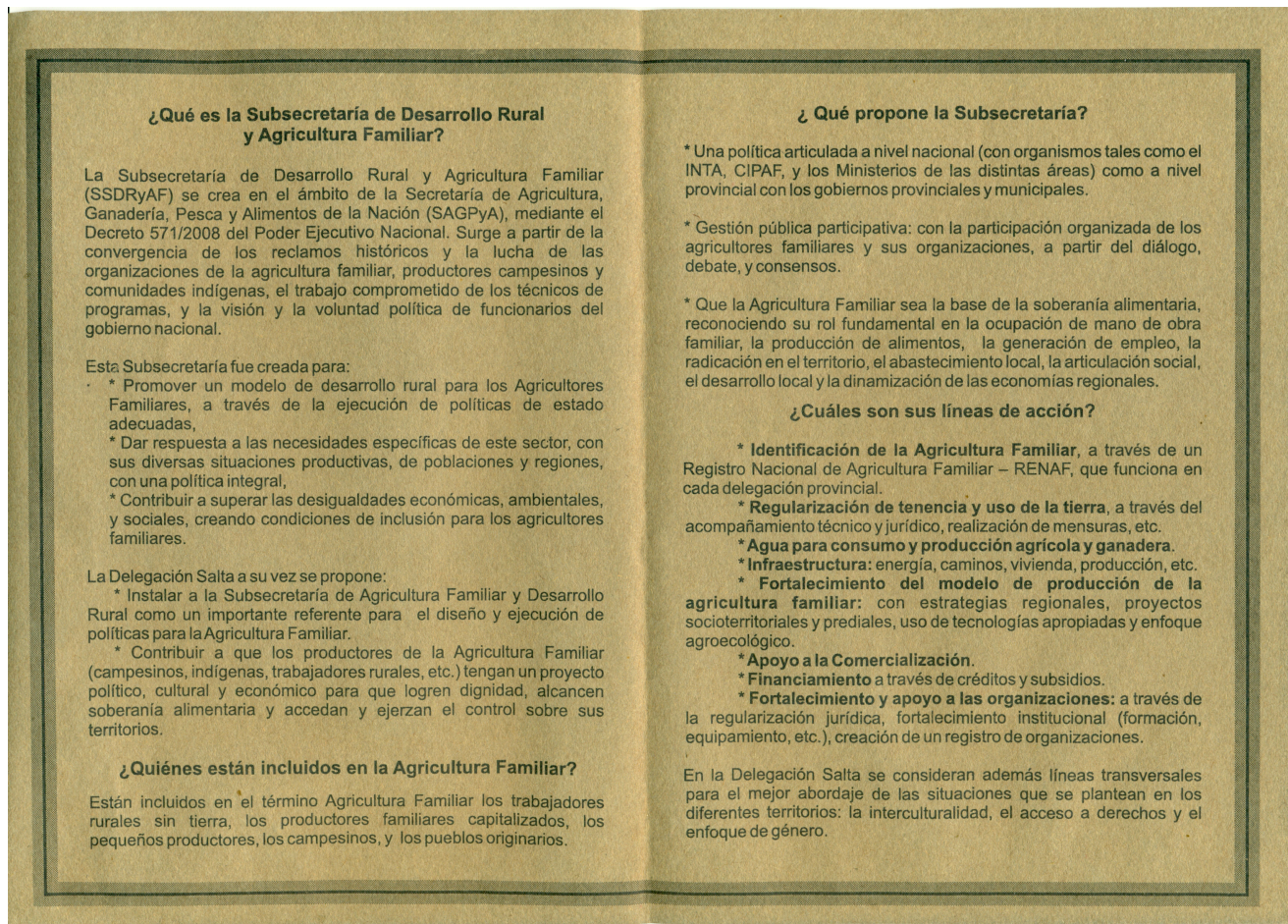

Figura 3. Subsecretaría de Desarrollo Rural y Agricultura Familiar - Delegación Salta "Información Institucional" 2. Undersecretary of Rural Development and Family Farming - "Institutional Information" Salta Office 2. 
Así, la Asociación de Comunidades Aborígenes de Nazareno-OCAN, y la Coordinadorade Organizaciones y Comunidades Kolla Autónomas de la Provincia de Salta, Qullamarka, las dos organizaciones más importantes a nivel provincial (por la fuerza numérica de las comunidades que las integran y la extensión territorial que ocupan) que llevaban varios años de funcionamiento, fueron fortalecidas e incorporadas a la estructura de la SsAF, a través de la designación de 'técnicos idóneos', figura que se presentará a continuación. Esta incorporación, conjuntamente con el cambio paradigmático de trabajo sobre unidades denominadas 'socioterritorios' (Figuras 4 y 5), produjo un cambio sustancial en el know-how de la SAF provincial.

El concepto de 'socioterritorio' revisa y cuestiona la noción hegemónica de 'territorio', entendido puramente como una escala estatal, o como una división netamente geopolítica; propone en cambio abordar estos lugares como espacios de disputa, productos de relaciones históricas de poder (Mançano Fernandes 2005). Incorporando algunas reflexiones impulsadas por los pueblos indígenas, el enfoque socioterritorial comprende el territorio en su multidimensionalidad: ritualidad, cultura, educación, producción, salud, vivienda, agua, y todos aquellos componentes y condiciones para desarrollar la dignidad humana (PSA 2007).

Si bien fue desarrollado en trabajos anteriores (Weinberg 2013, 2017), vale resumir que en el año 1993 se creó el Programa Social Agropecuario (PSA), como instrumento de Política Social (PSA 2001:15), dependiente de la entonces Secretaría de Agricultura, Ganadería y Pesca (SAGPyA) y creado inicialmente bajo el apoyo del Ministerio de Economía. Este Programa, antecesor de la SsAF, estaba "específicamente orientado a la atención del Pequeño Productor Minifundista" (PSA 2001:8), y tenía como objetivo principal dar respuesta a un sector que si bien siempre ha sido importante numéricamente, nunca había tenido una atención particular desde el Estado. Sin salirse de los lineamientos neoliberales de los noventa, en los inicios del PSA, se promovió el discurso del "emprendimiento", incorporando la lógica del microcrédito y fortalecimiento del ingreso al mercado a través de una mejora en la comercialización. Se creó un nuevo sujeto, el empresario indígena-campesino, no ya como integrante de una comunidad indígena sino como parte de un grupo de crédito (DeHart 2010). El PSA surgió entonces como una política

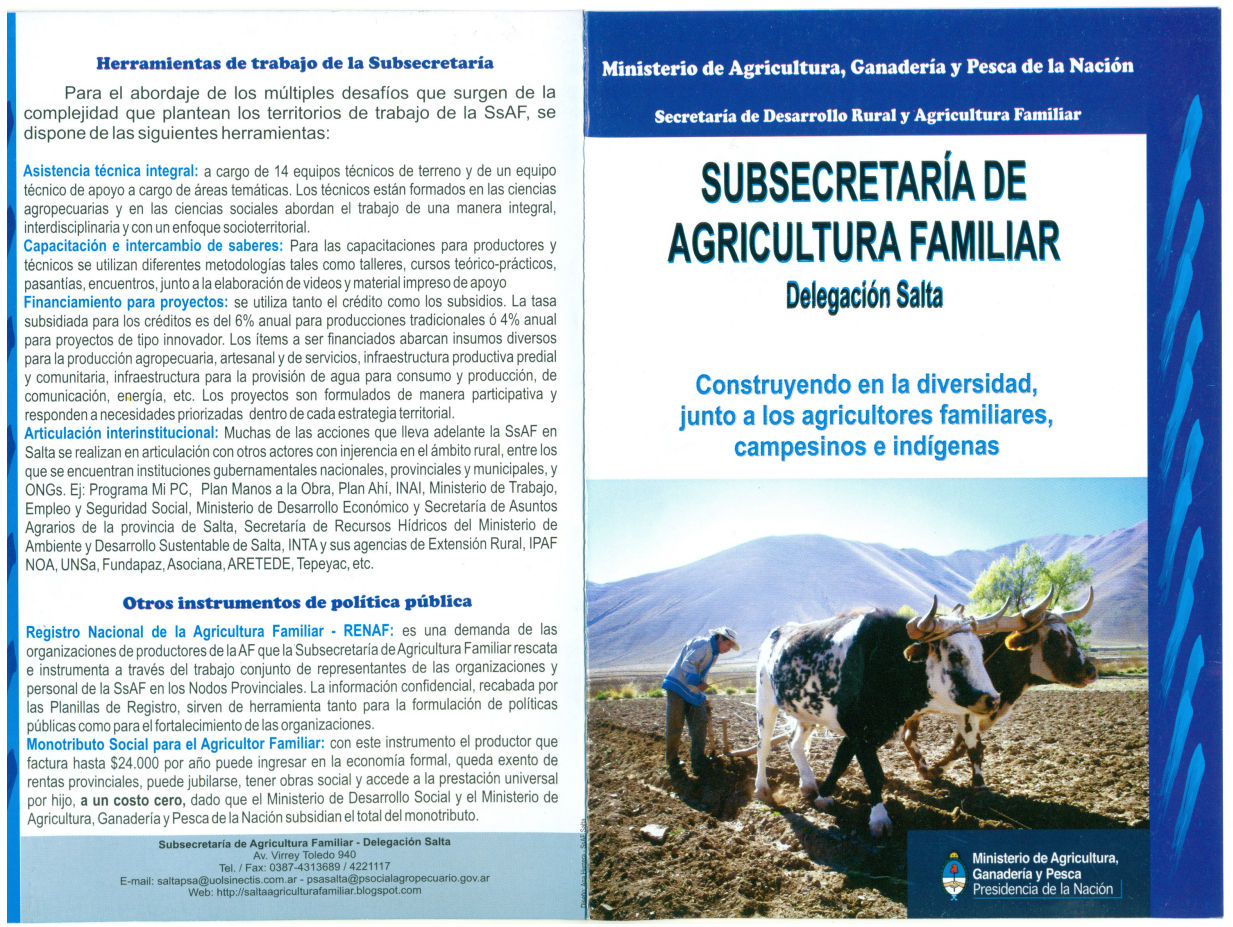

Figura 4. Subsecretaría de Desarrollo Rural y Agricultura Familiar - Delegación Salta "Herramientas de trabajo".

Undersecretary of Rural Development and Family Farming - “Working Tools” Salta Office 1. 


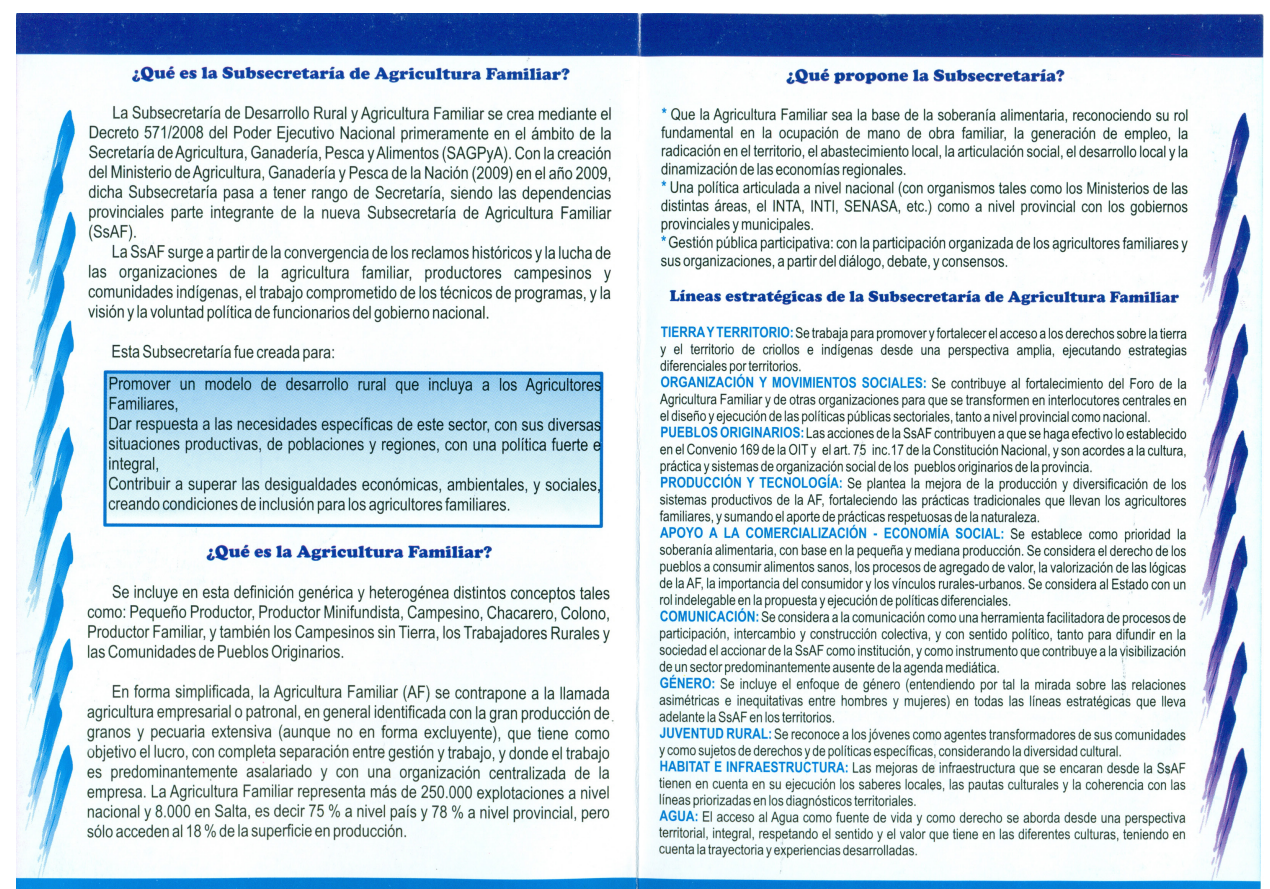

Figura 5. Subsecretaría de Desarrollo Rural y Agricultura Familiar - Delegación Salta “¿Qué es la Subsecretaría de Agricultura Familiar?".

Undersecretary of Rural Development and Family Farming - "What is the Undersecretary of Rural Development and Family Farming?" Salta Office.

pública para paliar la pobreza en medio del auge de medidas neoliberales, con una ejecución inicialmente temporal, pero que con el correr del tiempo se instituyó como política social de larga duración, al punto que se llegó a institucionalizar en el año 2006, pasando de ser Programa a Subsecretaría (de Agricultura Familiar).

En suma, ya desde 2005 el PSA había comenzado a reorientar sus políticas hacia un abordaje denominado 'socioterritorial', y en 2008, acompañando nuevas políticas de gobierno, se crea la Subsecretaría de Agricultura Familiar (SsAF), dentro del Ministerio de Agricultura, Ganadería y Pesca de la Nación. Como parte del nuevo mapa institucional, se constituye la Secretaría de Desarrollo Rural y Agricultura Familiar, dentro de la cual se instalan la SsAF y la Subsecretaría de Economías Regionales. De esta manera se remplazó un Programa por una Subsecretaría, manteniendo por completo la estructura de amplia cobertura nacional que tuvo desde sus inicios el PSA. La creación de la SsAF constituyó una política de Estado orientada al sector de la agricultura familiar, compuesto por pequeños productores. Este nuevo enfoque de la Subsecretaría, favoreció la comunicación con otras organizaciones e instituciones ya existentes o que fueron creadas bajo la misma lógica de apoyo a la agricultura familiar ${ }^{5}$. En este sentido, se fue encontrando un nicho de acción con políticas que se pensaron de manera más acabada y duradera, a diferencia de las focalizadas y ejecutadas de manera aislada principalmente por el Banco Mundial, del período anterior.

En primer lugar, el enfoque socioterritorial implantó la proposición fundamental de entender la unidad de trabajo, la unidad de desarrollo, ya no solamente desde una perspectiva productivista y focalizada, sino como un espacio producto de una construcción social y política, resultante de procesos históricos (Weinberg 2013). A diferencia de la etapa previa (década de los noventa) en la cual los técnicos implementaban y replicaban proyectos productivos focalizados y estandarizados a lo largo del país, este nuevo enfoque propuso considerar las particularidades sociales, culturales, históricas, económicas que conformaban el espacio, y desde allí pensar desde el diseño hasta la implementación del proyecto; lo que para el caso que observo en territorios ancestrales resulta fundamental, dada la complejidad histórica en la cual se encuentran inmersos. Y fue así que una definición política del espacio se fue instaurando a partir de la instauración del enfoque a través de la institucionalización del mismo (Figuras 6, 7 y 8).

En segundo lugar, la figura del 'idóneo' introducida anteriormente, no solamente implicó la afiliación de un técnico de terreno local, sino que 


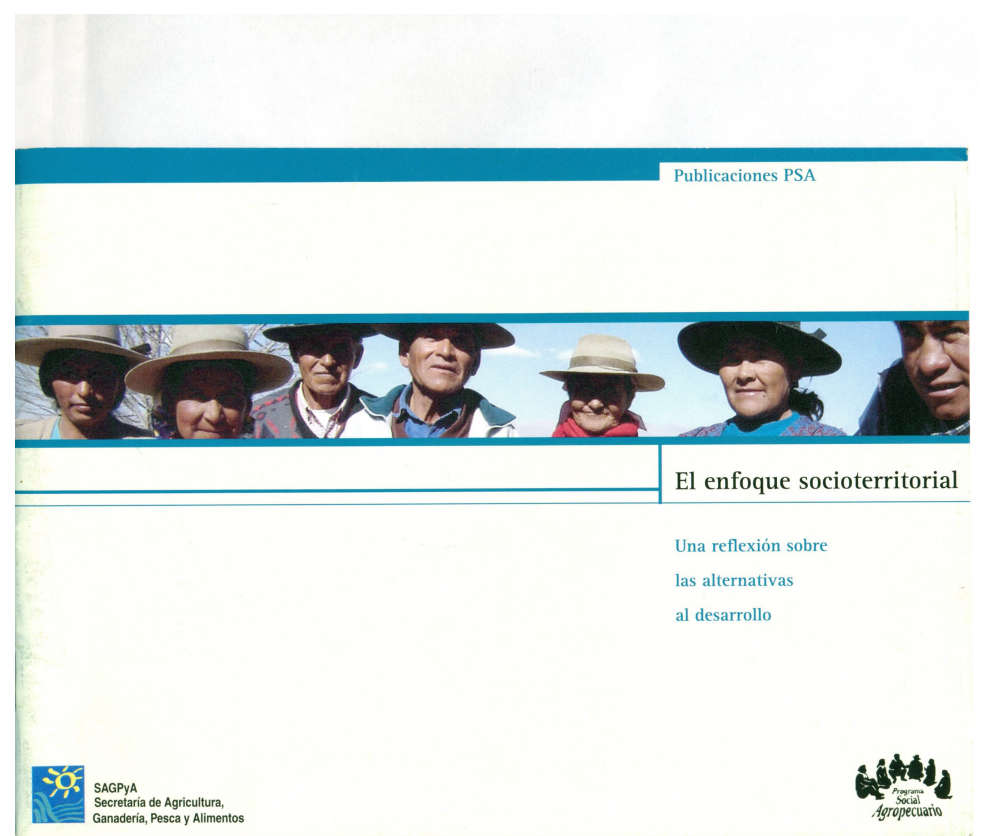

Figura 6. Subsecretaría de Desarrollo Rural y Agricultura Familiar - "El Enfoque Socioterritorial" 1. Undersecretary of Rural Development and Family Farming - "The socio-territorial Approach" 1.

\section{Introducción|}

En la actualidad el debate sobre la cuestión del territorio ocupa un lugar destacado en ámbitos muy diversos: en el mundo académico, en los foros nacionales e internacionales sobre políticas públicas o desarrollo, en espacios propios de las organizaciones locales: de vecinos, de indigenas, de campesinos, de ecologistas, de desocupados, de marginalizados urbanos, etcetera.

Desde una mirada ligera podría, con alguna razón, interpretarse que estamos frente a un "problema de moda", una clave de interpretación pasajera, circunstancial, sin embargo consideramos que esta percepción es errónea. Es cierto que han surgido recientemente y se han multiplicado los análisis que apelan a un enfoque territorial de forma creativa y novedosa. Es también cierto que el enfoque geográfico resurge potente y que la mirada en clave cartográfica opera ahora tanto en ciencias naturales, exactas como sociales. Desde las ciencias naturales y exactas, con ayuda de la tecnología satelital, es posible ejercer una mirada cartográfica en torno a la agricultura, la distribución de los recursos naturales, los procesos climáticos, etc.; a su vez, desde las ciencias sociales, se aplica una mirada cartográfica para interpretar los procesos globalizadores "de arriba" y "de abajo", mapear redes internacionales de alianzas y conflictos, conformar una matices de datos que tomen distintas escalas (local, nacional, regional y global). Sin embargo, esta ebullición, esta proliferación de herramientas de análisis en clave territorial, son en realidad el resultado del estallido social de un "problema" que, aunque haya sido desplazado, nunca abandonó la escena.

El objetivo de este trabajo es aportar a la construcción de un marco teórico del enfoque socio territorial y su relación con el desarrollo rural desde los aportes de la sociología y de la geografía. Aquí, dos conceptos se tornan clave y por lo tanto deben ser especificados. El primero supone abordar el espacio como categoria analítica para luego poder sumergimos en otro concepto de gran importancia para el enfoque: el de territorio.

Figura 7. Subsecretaría de Desarrollo Rural y Agricultura Familiar - "El Enfoque Socioterritorial” 2.

Undersecretary of Rural Development and Family Farming - "The socio-territorial Approach" 2. 


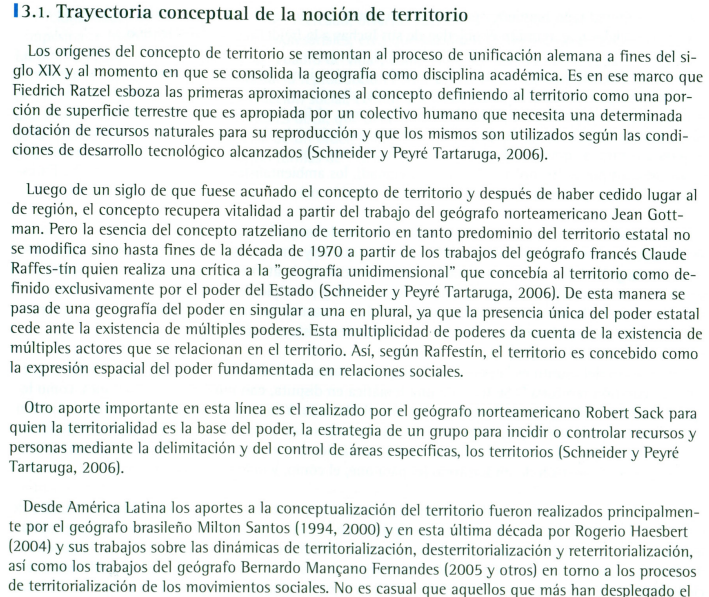

Figura 8. Subsecretaría de Desarrollo Rural y Agricultura Familiar - "El Enfoque Socioterritorial" 3.

Undersecretary of Rural Development and Family Farming - "The socio-territorial Approach" 3.

incorporó organizaciones indígenas a la estructura estatal, otorgándoles cierto nivel de autonomía a la hora de diseñar los proyectos que se ejecutarían en su territorio. La anexión de estos idóneos, reconoció capacidades y conocimientos no necesariamente legitimados por estudios formales, sino saberes y prácticas ancestrales locales que finalmente fueron reconocidas por el Estado a la hora de llevar adelante el diseño y ejecución de proyectos de mejoramiento en las comunidades. Dejando ver la complejidad de la definición y configuración desde los distintos espacios, un técnico idóneo de la localida de Iruya, representante de la organización indígena Qullamarka me dijo que "no se intentaba que un miembro de la comunidad kolla hiciese lo mismo que un técnico que vive en la ciudad, en Salta o Jujuy. La Subse buscaba que el idóneo fuese un recurso de la organización y no un espía para el Estado; no hubo nunca mala intención, pero sí tuvimos que pensar y discutir qué aporto, qué sumo, para no terminar solamente reproduciendo el discurso del desarrollo".

Muchos de estos idóneos, además de incorporarse como especialistas a la estructura de la SsAF, eran representantes de las comunidades indígenas de las cuales provienen, garantizando de alguna manera un alto grado de legitimación de la oficina a nivel local. Tal es el caso de la organización Qullamarka, la cual reúne a su vez, alrededor de setenta comunidades y organizaciones repartidas en un territorio de más de un millón de hectáreas de posesión ancestral ${ }^{6}$. En este sentido, se avaló que el interlocutor de la SsAF fuese no simplemente un individuo perteneciente a una comunidad, sino alguien que a la vez, fuese reconocido por las asambleas comunitarias; poniendo en práctica la propuesta de Cristóbal Kay para lograr el diseño de estrategias creativas de desarrollo rural, en donde la sociedad y el Estado negocian para lograr formas más inclusivas y participativas, considerando además que la principal causa de la pobreza rural es la desigualdad en la distribución tanto de las tierras como en el sistema de poder (Kay 2005, 2006).

Si bien la figura del 'técnico idóneo' fue incorporada por la SsAF, vale la pena detenerse aquí para una mejor comprensión, ahondando en lo que posiblemente fue el antecedente de este modelo; no tanto desde una perspectiva innovadora de contenidos e incorporación de saberes locales al diseño de los proyectos, sino sobre todo pensando en la estrategia de incorporación de líderes indígenas a la maquinaria del desarrollo local. Ya desde fines de los noventa, la Comunidad Indígena Kolla de Finca Santiago, hoy perteneciente a la Qullamarka, había sido seleccionada como una de las tres comunidades en todo el país para recibir una enorme inyección de dinero del Banco Mundial (Carrasco et al. 2008; Weinberg 2004, 2013). El proyecto Desarrollo de Comunidades Indígenas (DCI) fue ejecutado entre los años 2002 y 2006 . Uno de los primeros pasos dados 
por el DCI fue la formación de 'promotores' locales, bajo las directrices de las políticas de desarrollo que respondían a la lógica bancomundialista de los noventa, con el manejo de herramientas tales como la estrategia del marco lógico, y el uso de conceptualizaciones como 'participación' y 'empoderamiento' (Weinberg 2013).

Una de las diferencias entre períodos fue que en un primer momento, el eje de estos proyectos focalizados estaba puesto en las características culturales y étnicas de las comunidades indígenas, mientras que desde la denominación como Agricultores Familiares, ya entrados los años 2000, se procuró fortalecer un rol más productivo, caracterización que de alguna manera pareció disipar cierta fuerza política que organizaciones de base habían alcanzado años atrás mientras sostenían las demandas históricas sobre los territorios (Lapegna 2017).

Un técnico de terreno de la provincia de Salta que participó del diseño que reorientó las prácticas generales hacia lo socioterritorial, con la introducción de técnicos idóneos, comenta que uno de los logros alcanzados fue que una oficina estatal, financiase directamente a una organización indígena, para que ellos pudieses elegir a los especialistas que querían involucrar en su proyecto comunitario (a diferencia de tener que trabajar sí o sí con los técnicos de terreno asignados por la SAF, para el desarrollo de proyectos específicos a ejecutar por grupos de familia). En sus propias palabras: "Les venía bien un especialista en agua, pero también la posibilidad de tener alguien de la misma organización que esté ahí, que viva ahí y no tener que esperar a que venga aun técnico cada dos semanas, a trabajar con dos o tres familias solamente". A pesar de apoyo recibido por la misma SAF de la provincia hacia demandas relacionadas con lo territorial, la problemática de la tenencia y regularización de los territorios ancestrales nunc fue abordada con la fuerza política necesaria para modificar la crítica situación de los pueblos originarios.

Algunos de los nuevos 'idóneos' de la SsAF, habían sido en su momento 'promotores' del DCIBanco Mundial.Y es en este sentido que se puede hablar de un know how otorgado por la lógica desarrollista del Banco Mundial, y años más tarde, recuperada por una oficina estatal. Ayudándonos de una conceptualización de Miguel Bartolomé, resulta fructífero nombrar a estos actores como cultural brokers, quienes han sido validados tanto por sus comunidades de origen como por el Estado. Se trata de miembros de comunidades indígenas, agentes, mediadores (profesionales, líderes políticos, intelectuales), preparados para funcionar en diferentes contextos, capaces de negociar con las diversas partes, orientando sus gestiones hacia una mejora de su propio espacio de acción política (Bartolomé 1987:171).
Estos dirigentes, ahora representantes estatales, articuladores entre Estado y comunidad, lograron mayormente negociar prioridades y contenido de proyectos (mejoramiento de riego, de caminos, construcción de puestos comunitarios, capacitación en manejo de cultivos, cuidado de animales, desarrollo de la artesanía local, entre otros). A pesar de lo cual, como me dijo un entrevistado quien formó parte de diversas organizaciones sociales desde principios de los noventa, y luego tuvo también un breve paso por la SsAF de Jujuy, "nunca se puso en duda el modelo agrario". Y prosigue:

no creo que haya demasiados cambios estructurales más allá de lo que sea una política asistencialista. De fondo puede tener mejores características, puede tener un poquito más de llegada, puede ser más amplia, más participativas, pero en el fondo no hay una transformación de los problemas estructurales de la persona en el campo; puede ser que la producción valga un poco más y que puedan venderla bajo mejores condiciones en el mercado, pero los grandes [empresarios de agronegocios, principalmente sojeros] tienen subsidios y no lo tiene la producción campesina.

Estos actores, así como procuraron traer la voz de la comunidad, y lo hicieron, terminaron estando restringidos a los parámetros de acción de la SsAF a nivel nacional. Si bien de todas maneras se debe observar que la organización Qullamarka logró fortalecerse en términos de poder político a nivel provincial generando acciones que modificaron ciertas prácticas y políticas dentro de Salta (a lo largo de los años no se han detenido las importantes movilizaciones presionando a los poderes políticos para acelerar procesos de devolución territorial a nivel regional o de suspensión de desalojos por ejemplo), lo cierto es que no hubo cambios estructurales a nivel nacional que mejorasen las condiciones generales de las comunidades, sobre todo en relación a la tenencia y regularización territorial. Así como se pudieron acortar ciertas estrategias y prioridades, no hubo un movimiento hacia el desarrollo alternativo que pudiese luchar contra la universalidad territorial y epistemológica capitalista hegemónica (Escobar 2008).

Podemos pensar en este caso, la formación, o el fortalecimiento de una "burocracia indígena", que va aprendiendo a moverse dentro de los márgenes de la estructura estatal, pero procurando mantener cierta autonomía comunitaria, lo que resulta un equilibrio muy difícil de sostener. En el caso de la organización Qullamarka, la defensa de su autonomía está muy marcada por la decisión de no incorporarse ni 
formar parte de foros nacionales u organizaciones de base de mayor cobertura regional o nacional, así como no permitir que sus líderes representen oficialmente a partidos políticos en elecciones locales y provinciales; a pesar de lo cual, hay casos en los que esta directriz no se cumple.

Cabe decir también, que la coordinación y equipo técnico de la SsAF provincial, era contrario a las orientaciones políticas provinciales por lo que también resultaba difícil ejecutar ciertas estrategias debido a que eran contrarias a los intereses de los poderosos agronegocios que se han venido desarrollando por décadas en el NOA. Se puede decir entonces, que tanto la SsAF como los técnicos idóneos, tuvieron un papel ambivalente a lo largo del desarrollo de las políticas en el período estudiado. Así como la inclusión de la organización Qullamarka a la SsAF fue percibida por la mayoría de las comunidades como positiva, de más está decir que también provocó enormes discusiones, considerando que quienes están realmente afectados, son miembros de las comunidades que como se dijo anteriormente, cumplen una doble y muy compleja función: son empleados públicos implementando políticas de intervención estatal y al mismo tiempo, son representantes de los intereses de sus comunidades de origen. En este sentido, así como pueden facilitar el diálogo, quedan también atrapados como intermediarios en las negociaciones más profundas, las cuales no siempre favorecen los intereses comunitarios. Perspectivas internas más críticas, han visto la incorporación de idóneos como cooptación de sus líderes comunitarios, lo que redunda en una desactivación política de las organizaciones indígenas más fuertes del país. Como me comentó un poblador de la comunidad indígena kolla de Isla de Cañas, "ya el DCI [proyecto del Banco Mundial] había desactivado el discurso político, y dejaron una camioneta, dos vacas y encima nos dejaron divididos y con desconfianza. Hay que ver ahora cómo hace el Qullamarka para no enquistarse en el poder del Estado y olvidarse de nosotros".

Durante los noventa, el conocimiento local indígena del Sur, se erigió como un poder político capaz de producir un reservorio de alternativas al desarrollo, defendiendo la soberanía, negociando estrategias y creando representaciones particulares (Edelmand y Huagerud 2007). Discursos monolíticos sobre el desarrollo fueron desafiados por la emergencia de movimientos que resultaron de procedimientos burocráticos y prácticas locales. Sin embargo, algunos también critican que estos movimientos escencializaron y romantizaron el conocimiento local; e inclusive, presentando alternativas viables, no se logró generar un debate masivo sobre las políticas de desarrollo de manera estructural (Weinberg 2017). En este sentido, como conclusión se sugiere que la incorporación de los técnicos de terreno idóneos a la SsAF no constituyó estrictamente una modalidad novedosa que tuviese que ver con una redefinición estructural de políticas estatales o demandas indígenas, sino que, sin descartar su importancia, representaba la incorporación de conocimiento local, a través de agentes reconocidos y legitimados por el Estado, a la máquina de políticas de desarrollo rural iniciada en los años noventa bajo el signo neoliberal.

Retomando las conceptualizaciones de hegemonía planteadas al inicio, resulta útil a esta altura del trabajo, hacer hincapié en el rol fundamental que resultan tener los intermediarios de la ejecución de políticas públicas, quienes terminan siendo los que, en última instancia, ejecutan, pero también negocian, moldean, muchas veces adaptando a sus propios intereses, la mera materialización de las políticas estatales nacionales que se aplican en espacios locales. En este caso, fueron los técnicos idóneos quienes en su mayoría adquirieron conocimientos y entrenamiento durante los noventa, bajo el paradigma de desarrollo implementado por el Banco Mundial, y luego durante el 2000 pasaron a ser parte de la estructura estatal.

Para cubrir el espacio territorial que cubre la organización Qullamarka, se nombraron cuatro técnicos idóneos y luego se llevó a cabo un estudio de "diagnóstico socioterritorial participativo" para relevar condiciones, necesidades y prioridades (accesibilidad, educación, acceso al agua, condiciones infraestructurales, puestos de salud, etc.), los cuales fueron discutidos por las asambleas comunitarias. Una vez culminado este primer estudio, se respetaron las peticiones de la organización de base para implementar los proyectos requeridos. Mientras que la delegación de la SsAF de Salta amplió enormemente el alcance de sus estrategias a zonas muy aisladas (considerando la dificultad de acceso a través de vías carreteras), y generó espacios de participación y negociación, articulados con comunidades locales, no se logró poner en marcha un mecanismo o apertura de espacios para debatir de raíz las condiciones de escasez material y acciones políticas (relaciones de poder altamente desiguales) que en realidad generan las situaciones de pobreza extremas que padecen estas poblaciones (Kay 2006). Si bien hubo una evidente apertura hacia la problemática del sector, no se logró poner sobre el tapete temas estructurales y estructurantes como la autonomía indígena y la devolución de territorios ancestrales, de una manera más definitiva (Domínguez 2009). Así, el modelo agro-exportador que incorpora a Argentina al mercado global, no ha cambiado de manera firme por más de un siglo. Tampoco se han incorporado miradas novedosas al diseño de políticas que modifiquen y protejan el manejo de 
recursos naturales, los cuales siguen favoreciendo condiciones de concentración de tierras, deforestación, expropiación de territorios ancestrales, beneficiando capitales extranjeros a través de la producción de soja transgénica, ganadería extensiva y minería a gran escala, entre otros emprendimientos (Lapegna 2018). Un histórico referente de la comunidad de Colanzuli, me dice en este sentido que la SsAF "no ha generado políticas distintas, no ha podido plantear un modelo productivo distinto". Y prosigue:

cuando surgió el problema sojero todos se guardaron, mira declaraciones del INTA [Instituto Nacional de Tecnología Agropecuaria], de la SAF, nadie dijo nada. Nunca nos había pasado que el modelo se debatía en todos lados, y así y todo, no decían nada. Ahora todo el mundo habla de la soja, pero cinco años atrás nadie decía nada. De la minería...hoy se habla, pero ninguna de estas oficinas planteó políticas distintas.

\section{Repensando a las Organizaciones Sociales después de 2003}

Como fue introducido anteriormente, las reorientaciones del modelo estatal reconfigurado desde el año 2003 afectaron a las esferas públicas relacionadas con el desarrollo rural, e influenciaron sobre diferentes niveles en la configuración de movimientos sociales. Cuando no se intenta presentar dicho período como panacea, aún se debe rescatar que comparado con el anterior de políticas neoliberales extremas desarrollado ampliamente durante la década de 1990, los pueblos indígenas y sectores rurales devinieron en activos actores, beneficiarios, y hasta expertos en una serie de estrategias orientadas a su propio sector. A pesar de ello, estas políticas fueron mayormente compensatorias ya que como se señaló, la matriz económica estructural no se modificó. Bajo este contexto, algunas organizaciones comenzaron a redefinirse, estableciendo nuevos canales de comunicación y repensando el rol del Estado, así como su vinculación con el mismo; algunas organizaciones sociales se incorporaron a la estructura estatal, manteniendo y/o negociando constantemente los niveles de autonomía, y algunas otras, decidieron no sumarse de ninguna manera a la estructura pública.

La organización Qullamarka fue asociada a la SsAF de Salta algún tiempo después de su conformación en 2007. Este proceso coincidió con las nuevas estrategias que estaba adoptando dicha oficina, como fue presentado anteriormente, lo cual propuso una forma de trabajo más participativa (Weinberg 2013). La novedad de dicha organización fue entonces crear un espacio supracomunitario, que integrase a todas las comunidades kolla de esta región. El territorio total de la organización incluye terrenos privados (actualmente en manos de propietarios externos a las comunidades), tierras comunitarias indígenas con títulos de propiedad otorgados, otros en proceso de regularización, en litigio, jurisdicciones nacionales como parques, áreas protegidas y hasta recursos hídricos. Este recorte territorial, contiene espacios sobre distintos departamentos de la provincia de Salta (Iruya, Santa Victoria y Orán) lo que genera constantemente una superposición de unidades estatales administrativas y uso del espacio ancestral, lo que a veces dificulta su funcionamiento comunitario. A pesar de lo cual, es de destacar que la formación de la organización Qullamarka, permitió ampliar el espacio geográfico de acción, así como la fuerza de las demandas que dejaron de ser específicas de una comunidad, y pasaron a ser defendidas por un colectivo mucho más amplio, superando las directrices focalizadas que había impuesto el Banco Mundial con su proyecto DCI una década atrás, inyectando enormes sumas de dinero en pequeñas localidades.

En el año 2006 se sancionó en Argentina la ley nacional 26.160 de Relevamiento Territorial, la cual declara la "emergencia en materia de posesión y propiedad de las tierras que tradicionalmente ocupan las comunidades indígenas originarias del país" y suspendió los procesos de desalojos que afectaban a las tierras de las comunidades. Con el objetivo de relevar la situación dominial de las tierras ocupadas y reclamadas por los pueblos indígenas, el Instituto Nacional de Asuntos Indígenas puso en marcha un enorme dispositivo que a la fecha no ha logrado dar sus frutos debido a la incapacidad técnica y presupuestaria anteriormente mencionada.

De alguna manera la creación de la Qullarka, tuvo también como objetivo principal dar fuerza y ampliar los márgenes de negociación de este tipo de programa, al constituirse como una fuerza política a nivel provincial. La organización fue establecida como un lugar de discusión para volcar preocupaciones comunes y establecer estrategias compartidas a la hora de negociar con el Estado tanto nacional como provincial, y con otros actores externos. También cabe decir que a medida que ha pasado el tiempo, han logrado redefinir objetivos y estrategias, acompañando los cambiantes contextos políticos, pero tratando de sostener demandas más estructurales tales como autodeterminación, y devolución y regularización legal de territorios ancestrales.

Desde sus inicios, la organización Qullamarka se ha erigido con un incansable trabajo en la región, organizando asambleas comunitarias para garantizar que los debates y demandas más locales lleguen hasta la cúpula de la organización y viceversa. Logrando 
de esa manera también, cierta autonomía, o al menos independencia de las oficinas estatales que apuntalan su trabajo, tal como la SsAF. A la vez, suelen no ser escuchados o muchas veces deben terminar negociando en términos que no necesariamente los favorecen.

Uno de los técnicos idóneos del departamento de Orán relata que la SsAF incorporó el territorio cubierto por la Qullamarka como una unidad de trabajo; reconociendo entonces a la organización como representante de las comunidades indígenas kolla allí asentadas: "La organización Qullamarka ha construido su propio mapa del territorio kolla, mostrando que los territorios por los que luchamos forman parte de un conjunto que tiene una historia en común. Y una oficina estatal no la va a fragmentar". Fue así, que la Secretaría aceptó, y en lugar de utilizar un mapa 'oficial' de la provincia de Salta, tomaron nota y trabajaron sobre el territorio reclamado por esta organización indígena, asumiendo una postura política muy importante, sobre todo en un contexto provincial siempre adverso a los pueblos originarios. Y aún, reconociendo que partes del territorio reclamado por la organización, a la fecha, están bajo manos privadas nacionales y extranjeras que lo explotan, con conocimiento y aval de la gobernación de la provincia.

Los representantes de la Qullamarka expresan con profundo orgullo que esta experiencia de organización y trabajo dentro de la SsAF les permitió fortalecer vínculos de solidaridad hacia adentro del territorio que ocupan, permitiéndoles trabajar de manera conjunta y priorizando a las comunidades que se encuentran con mayores deficiencias que el resto. En la actualidad declaran, no hay ni una sola comunidad dentro de su territorio que no haya sido beneficiada de alguna manera por la SsAF. La atención tan masiva recibida, es atribuida íntegramente a la incorporación de los técnicos 'idóneos', representantes de la Qullamarka, asî como a la permeabilidad que tuvo la gestión provincial de la SsAF en recibir y trabajar en base a los intereses comunitarios.

Considerando el viraje político sufrido en Argentina a lo largo de los últimos dos años, debemos observar ahora de qué manera la reorientación política de la actual SsAF, tanto a nivel nacional como provincial, actúa sobre los proyectos en territorio, asî como la forma en la cual la organización se desenvuelve teniendo en cuenta la experiencia de la última década. En este sentido, la provincia de Salta es la primera en el país en crear un Ministerio de Asuntos Indígenas y Desarrollo Comunitario (2016), lo cual también inicia un nuevo período respecto de las articulaciones entre la Qullamarka y el estado provincial, independientemente de las acciones que se sigan tomando desde la actual SsAF.

Con una muy corta trayectoria y a partir de las intenciones expresadas por el Ministro de dicha oficina en una entrevista, pareciera ser que la disposición del trabajo de dicha oficina se acercará a obras propias del asistencialismo, que en el mejor de los casos, se volverá a acercar más hacia un apuntalamiento de lo cultural, que a lo político-económico, tal y como sucedió durante los noventa. Desde el año 2016, tanto en las oficinas de Salta como de Jujuy ha habido fuertes recortes presupuestarios que han dejado sin trabajo a casi un tercio de los trabajadores, y desde entonces la SsAF vive bajo amenazas constantes de un futuro cierre total.

\section{Reflexiones Finales}

Este artículo examinó la vinculación entre la reconfiguración de una organización indígena y el diseño de políticas públicas orientadas al sector, bajo la denominación de agricultura familiar, principalmente entre el 2003 y el 2015. Este análisis, nos permite observar cambios, no solamente en las denominaciones de los actores por parte del Estado sino en diversos niveles organizacionales de participación, así como en la relación entre de diseño de políticas públicas y estrategias comunitarias, y finalmente en sus relaciones con otros actores sociales.

Considerando los objetivos y el abordaje teórico del estudio, no resulta provechoso pensar y analizar estos espacios como monolíticos o estáticos, y es en este sentido que a lo largo de los años hemos observado cómo las instituciones y organizaciones se van reformulando en su forma y contenido, modificando sus objetivos y estrategias, y han ido revisando también las formas de relacionarse con otros actores sociales, negociando pujas e intereses de los actores involucrados.

Así como considero válido aseverar que la licuadora del multiculturalismo neoliberal de los noventa estableció parámetros muy determinantes para el reconocimiento a la diversidad étnica, el ampliamente analizado indio permitido (Hale 2004), poniendo de relieve casi exclusivamente aspectos culturales, debemos prestar atención también a los efectos que han tenido los procesos de denominación tan fuertes, como ha sido el caso de la Agricultura Familiar, con los cuales se corre el riesgo de oscurecer historias de lucha, trayectorias y debates político-económicos estructurales que sin dudas han definido y moldeado a los movimientos indígenas por tanto tiempo.

La estrategia de intervención rural desplegada por la SsAF (a través de la incorporación de los técnicos idóneos y de la creación de la unidad socioterritorial) generó por un lado que se lograse un acercamiento importante a las comunidades y por el otro, se modificó la lógica institucional. A pesar de lo cual, sobre todo considerando los enormes esfuerzos a nivel local, la Subsecretaría no logró generar cambios estructurales a 
nivel nacional, ni en relación al acceso y regularización de tierras ni a la estructura productiva nacional. Como señala Lapegna, si bien los gobiernos sucesivos de los Kirchner confrontaron con los sectores dominantes, ni "la base material de las desigualdades rurales ni la distribución desigual del poder a escala sub-nacional" fueron profundamente modificados. Y prosigue: "por el contrario, sus administraciones apoyaron la expansión del agro-negocio, favoreciendo a las corporaciones globales y promoviendo una mayor adopción de la biotecnología agrícola" (Lapegna 2018:159).

Si bien en muchos casos estas políticas de inclusión buscaron no solamente mejorar la calidad de vida, sino también los ingresos y las condiciones de las familias rurales, lo cierto es que el modelo masivo extractivista que asola al país, no se ha detenido. Estas circunstancias ilustran de alguna manera uno de los principales argumentos que subyacen a este artículo: en el contexto político finalizado a fines del 2015 , observamos la confluencia de diversos elementos tales como formas más inclusivas y equitativas de gobernabilidad, pero aún con superviviencias neoliberales muy fuertes. En otras palabras, mientras se financiaron proyectos para sectores desprotegidos como el de la denominada Agricultura Familiar, se siguieron sosteniendo estrategias a gran escala que fortalecieron un modelo agro-exportador que sigue perpetuando inequidades estructurales, manteniendo la concentración de enormes extensiones de tierra y en muchos casos su explotación intensiva a manos de capitales extranjeros, en detrimento del desarrollo de los pequeños productores locales.

Desde la perspectiva de las organizaciones de base, y el caso particular de la Qullamarka, se ha detenido al menos por ahora, la posibilidad de seguir planificando y ejecutando proyectos desde la SsAF porque la misma está siendo desguazada a nivel nacional bajo el gobierno de Mauricio Macri, y con especial ahínco en las provincias del NOA. Aunque se pueda pensar que la incorporación de técnicos idóneos, celebrada durante su ejecución porque fortalecía a la organización comunitaria, con el inicio del nuevo contexto político funcionó casi en contra debido a una suerte de desactivación política del período anterior, se debe decir que si bien la organización Qullamarka encontró un estado de latencia en relación a su actividad política pública, nunca dejó de manifestarse especialmente en relación a demandas territoriales dada la emergencia en la cual se encuentra la provincia de Salta por el avance de los desmontes desde hace décadas. Es decir, la cooptación que pudo haber resultado de la incorporación formal de las comunidades a la estructura estatal, no presentó de ninguna manera una desactivación política total. Las demandas de autonomía y defensa de los territorios fue siempre una bandera de lucha de los pueblos indígenas, y nunca claudicó; y ahora vemos que con la administración actual, se ha radicalizado nuevamente.

Desde diciembre de 2015, con la asunción de la administración macrista a la presidencia, las estrategias orientadas a pequeños productores, campesinos y comunidades indígenas han estado bajo amenaza de desaparición. En este sentido, todas las oficinas creadas bajo el paraguas de la Agricultura Familiar en el período política anterior, están siendo cercenadas desde el inicio de la gestión del nuevo gobierno, siendo las oficinas de la SsAF de Salta y Jujuy de las más afectadas del país. En concordancia, se ha reducido la planta permanente de los trabajadores de varias delegaciones provinciales y se ha recortado prácticamente a cero el presupuesto de trabajo en terreno. Estas medidas han sido tomadas de manera dramática por las organizaciones y los pobladores locales, tal y como declara un diputado provincial por el Frente para la Victoria:

Eso es un golpe fuerte a las organizaciones. Dejan a nuestros pueblos huérfanos. Los dejan sin esos técnicos, profesionales, especialistas que te dicen cómo hacer un chiquero, cómo mejorar el riego por goteo, cómo encarar un litigio legal por la tierra; todo eso ya no está más y forma parte de la política del Gobierno nacional de ajuste y achicamiento de lo que considera gasto social (El Tribuno, 5 de noviembre de 2018) 7 .

Otras instituciones abocadas como se presentó a la problemática de los pueblos originarios tales como el Instituto Nacional de Asuntos Indígenas, están sufriendo un recorte presupuestario similar, no pudiendo generar ningún tipo de intervención. De manera más drástica, en los primeros meses del año 2017, se cerró el Programa Nacional de Educación Intercultural Bilingüe, el cual garantizaba la difusión de los derechos adquiridos a través de la reforma constitucional en las poblaciones indígenas de todo el país (formando docentes y habilitando escuelas interculturales bilingües con material pedagógico $\mathrm{ad}$ hoc). A pesar de ello, la organización Qullamarka ha logrado defender las tres sedes del Profesorado Intercultural Bilingüe (en Iruya, Isla de Cañas y Tartagal), a través de negociaciones con el Ministerio de Educación de la provincia.

Respondiendo a los cambios políticos sucedidos en los últimos tres años en el país, se han generado dos preocupaciones mayores en relación a las problemáticas trabajadas en este artículo. En primer lugar, estamos asistiendo al desmantelamiento de instituciones estatales orientadas al apoyo a las poblaciones rurales más vulnerables. Despidos masivos y el abandono de las políticas ofrecidas a la agricultura familiar, 
demuestran el desinterés actual en el sector. En segundo lugar, la mayoría de las estrategias del actual gobierno, dejan a la vista la intención de la destrucción del entramado y organización social, promoviendo acciones y discursos individualistas por sobre los colectivos. Y yendo más lejos aún, erigiendo a los movimientos sociales como uno de los principales enemigos del actual gobierno.

Agradecimientos: Agradezco la atenta y minuciosa lectura realizada por los evaluadores externos.

\section{Referencias Citadas}

Abrams, P. 1988. Notes on the Difficulty of Studying the State (1977). Journal of Historical Sociology 1 (1):58-89.

Auditoría General de la Nación 2016. Informe de Auditoría. Instituto Nacional de Asuntos Indígenas. AGN, Buenos Aires.

Bartolomé, M.A. 1997. Gente de Costumbre y Gente de Razón. Las Identidades Étnicas en México. Siglo XXI, México DF.

Bisio, R.H. y F. Forni 1976. Economía de enclave y satelización del mercado de trabajo rural. El caso de los trabajadores con empleo precario en un ingenio azucarero en el noroeste argentino. Desarrollo Económico. Revista de Ciencias Sociales 61:16-61.

Bossert, F. 2012. Notas sobre la jerarquía interétnica en los ingenios azucareros del noroeste argentino. En Las Tierras Bajas de Bolivia: Miradas Históricas y Antropológicas, editado por D. Villar e I. Combes, pp. 217-236. Museo de Historia de la Universidad Autónoma Gabriel René Moreno, Santa Cruz de la Sierra.

Briones, C. (ed.) 2005. Cartografías Argentinas. Políticas Indigenistas y Formaciones Provinciales de Alteridad. Editorial Antropofagia, Buenos Aires.

Campi, D. y M. Lagos 1991. Auge azucarero y mercado de trabajo en el noroeste argentino, 1850-1930. Andes. Antropología e Historia 6:179-208.

Carrasco, M., M. Weinberg y L. Sterpin 2008. Entre la cooperación y la asistencia: un análisis de la incidencia del apoyo económico internacional en el movimiento indígena en Argentina. Revista Avá 12:9-26.

de la Cadena, M. 2006. The production of other knowledges and its tensions. From Andeanist anthropology to interculturalidad? En World Anthropologies. Disciplinary Transformations Within Systems of Power, editado por G.L. Ribeiro y A. Escobar, pp. 201-224. Berg, New York and Oxford

DeHart, M. 2010. Ethnic Entrepreneurs: Identity and Development Politics in Latin America. Standford University Press, Standford.

Domínguez, D. 2009. La Lucha por la Tierra en Argentina en los Albores del Siglo XXI. La Recreación del Campesinado $y$ de los Pueblos Originarios. Tesis Doctoral, Facultad de Ciencias Sociales, Universidad de Buenos Aires, Buenos Aires.

Edelman, M. y A. Haugerud (eds.) 2007. The Anthropology of Development and Globalization. from Classical Political Economy to Contemporary Neoliberalism. Blackwell, Malden.

Escobar, A. 2008. Territories of Difference: Place, Movements, Life, Redes. Duke University Press, Durham.

Friedman, J. 2003. Globalization, dis-integration, reorganization: The transformation of violence. En Globalization, the State and Violence, editado por J. Friedman, pp.1-34. Altamira Press, Walnut Creek.
Gledhill, J. 2000. Power and its Disguises. Anthropological Perspectives on Politics. Pluto Press, London.

Gledhill, J. 2004. Neoliberalism. En A Companion to the Anthropology and Politics, editado por D. Nugent y J. Vincent, pp. 332-348. Blackwell, Oxford.

Gledhill, J. 2008. Introduction: Anthropological perspectives on indigenous resurgence in Chiapas. Identities: Global Studies in Culture and Power 15 (5):483-505.

Gordillo, G. y S. Hirsch 2003. Indigenous struggles and contested identities in Argentina histories of invisibilization and reemergence. The Journal of Latin American Anthropology 8:4-30.

Gramsci, A. 1971. State and Civil Society. Prison Notebooks. Columbia University Press, New York.

Hale, C. 2002. Does multiculturalism menace? Governance, cultural rights and the politics of identity in Guatemala. Journal of Latin American Studies 34:485-524.

Hale, C. 2004. Rethinking indigenous politics in the Era of the 'Indio Permitido'. NACLA Report on the Americas 38 (2):16-21.

Harvey, D. 2003. The New Imperialism. Oxford University Press, Oxford.

Harvey, D. 2005. A Brief History of Neoliberalism. Oxford University Press, Oxford

Kay, C. 2005. Estrategias de vida y perspectivas del campesinado en América Latina. Revista ALASRU Nueva Época 1:1-46.

Kay, C. 2006. Rural poverty and development strategies in Latin America. Journal of Agrarian Change 6 (4):455-508.

Lapegna, P. 2017. The political economy of the agro-export boom under the Kirchners: Hegemony and passive revolution in Argentina. Journal of Agrarian Change 17 (2):313-329.

Lapegna, P. 2018. La economía política del boom agro-exportador bajo los Kirchner: Hegemonía y revolución pasiva en Argentina. En La Cuestión Agraria y los Gobiernos de Izquierda en América Latina: Campesinos, Agronegocio y Neodesarrollismo, editado por C. Kay y L. Vergara-Camus, pp. 155-188. CLACSO, Ciudad Autónoma de Buenos Aires.

Mallon, F.E. 1983. The Defense of Community in Peru's Central Highlands: Peasants Struggle and Capitalist Transition, 18601940. Princeton University Press, Princeton.

Mançano Fernandes, B. 2005. Movimentos socioterritoriais e movimentos socioespaciais. Contribuição teórica para uma leitura geográfica dos movimentos sociais. OSAL 6 (16):273-283.

Mann, M. 1993. A Theory of the Modern State. The Sources of Social Power. Volume II. The rise of classes and nation-states, 1760-1914. Cambridge University Press, Los Angeles.

Nugent, D. 1997. Modernity at the Edge of Empire. State, Individual, and Nation in the Northern Peruvian Andes, 1885 1935. Stanford University Press, Stanford. 
Nugent, D. 2004. Governing States. En A Companion to the Anthropology and Politics, editado por D. Nugent y J. Vincent, pp. 198-215. Blackwell, Oxford.

Postero, N. 2007. Now We Are Citizens. Indigenous Politics in Postmulticultural Bolivia. Stanford University Press, Stanford.

Programa Social Agropecuario 2001. El Programa Social Agropecuario 1993-2001. 8 años de Promoción y Apoyo a Pequeños Productores Minifundistas. Programa Social Agropecuario, SAGPyA, Buenos Aires.

Programa Social Agropecuario 2007. El enfoque socioterritorial. Una reflexión sobre las alternativas al desarrollo. Programa Social Agropecuario, SAGPyA, Buenos Aires.

Sayer, D. 1994. Everyday forms of state formation: Some dissident remarks on 'hegemony'. En Everyday Forms of State Formation. Revolution and the Negotiation of Rule in Modern Mexico, editado por G.M. Joseph y D. Nugent, pp. 69-106. Duke University Press, Durham.

Trinchero, H. y J.M. Leguizamón 1995. Fronteras de la modernización. Reproducción del capital y de la fuerza de trabajo en el umbral del Chaco argentino. En Producción Doméstica y Capital. Estudios de la antropología económica, editado por H. Trinchero, pp. 15-44. Biblos, Buenos Aires.

Vilas, C. M. 2011. Después del Neoliberalismo: Estado y Procesos Políticos en América Latina. Ediciones UNLa, Buenos Aires.

Weinberg, M. 2004. Identidades y organización política en la Comunidad Kolla de Finca Santiago. Iruya, Salta. Estudios Sociales del NOA 7:43-65.

Weinberg, M. 2013. Descubriendo el desarrollo: políticas de Estado y política indígena en el Noroeste Argentino. Una nueva era post-neoliberal? Perspectivas de Políticas Públicas 2 (5):77100.

Weinberg, M. 2017. From the Neoliberal State to a NeoNational development in Northwestern Argentina. Latin American Perspectives 44 (4):152-167.

Wolf, E. 2001. Pathways of Power. Building an Anthropology of the Modern World. University of California Press, Berkeley.

\section{Notas}

${ }^{1}$ A pesar de conocer el devenir de esta oficina con distintas jerarquías (Programa, Subsecretaría, Secretaría, y Subsecretaría nuevamente) y con variada pertenencia ministerial (Ministerio de Agricultura, Ganadería y Pesca, Ministerio de Agroindustria, Ministerio de Desarrollo Social), la denominaré como Subsecretaría de Agricultura Familiar (SsAF) a lo largo del texto, tal y como es su actual jerarquía, para evitar confusiones.

2 Ver Bisio y Forni 1976, Bossert 2012, Campi Lagos 1995, Trinchero y Leguizamón 1995, Weinberg 2013, entre otros.

${ }^{3}$ He desarrollado esta conceptualización hacia el fortalecimiento de la agricultura familiar en otros artículos por lo que no redundaré en detalles (Weinberg 2013, 2017).

${ }^{4}$ Considerando que a la fecha hay una elevada precariedad laboral entre los trabajadores de la SAF de Salta y Jujuy, así como situaciones que ponen en riesgo la integridad física de miembros de las comunidades indígenas debido al recrudecimiento del autoritarismo tanto en estas provincias como a nivel nacional, he decidido realizar una breve presentación, descripción, de los entrevistados pero omitir todo tipo de nombre o seudónimo.

${ }_{5}^{5}$ El coordinador a cargo de la transición hacia la nueva orientación de la SsAF, cuando aún era Programa Social Agropecuario, representaba al ya existente Movimiento Nacional Campesino Indígena (MNCI). En este sentido se podría decir que este cambio formó parte de un mensaje sumamente político, el cual dejó ver el apoyo estatal al desarrollo de un sector del campesinado más politizado.

${ }^{6}$ Comunidad Indígena de la Alta Cuenca del Río Lipeo, Consejo Indígena Kolla, Unión de Comunidades Aborígenes de Santa Victoria Oeste, Asociación de Comunidades Aborígenes de Nazareno y la Comunidad del Pueblo Kolla de San Andrés-Tinkunaku.

${ }^{7}$ El Tribuno, https://www.eltribuno.com/salta/nota/2018-5-90-0-0-provincia-recibio-a-las-organizaciones-campesinas. 
